\title{
Index of Algorithms
}

Denominators Algorithm, 89

Diagonalization Algorithm, 77

Discriminants Ideal Radical Algorithm, 63

Hess' Algorithm, 81

Hess' Algorithm for Rational Function Fields, 83

Idealizer Algorithm, 65

Integral Points 1 Algorithm, 112

Integral Points 2i Algorithm, 106
Integral Points 2ii Algorithm, 109

Integral Points 3 Algorithm, 99

Inverse Ideal Algorithm, 65

Norm Equation Algorithm 1, 91

Norm Equation Algorithm k, 92

Reduced Basis Algorithm, 73

Trager's Algorithm, 67 